\title{
Spinal pain in pre-adolescence and the relation with screen time and physical activity behavior
}

\author{
Anne Cathrine Joergensen ${ }^{1 *}$, Katrine Strandberg-Larsen', Per Kragh Andersen², Lise Hestbaek ${ }^{3,4}$ and \\ Anne-Marie Nybo Andersen ${ }^{1}$
}

\begin{abstract}
Background: To investigate how screen time and physical activity behavior were associated with spinal pain in pre-adolescence.

Methods: This study included 45,555 pre-adolescents who participated in the 11-year follow-up of the Danish National Birth Cohort. The 11-year follow-up included self-reported information on computer and TV behavior, aspects of physical activity, as well as frequency and intensity of spinal pain (neck-, mid back- and low back pain). Data were linked with parental socioeconomic data from Statistics Denmark registers. Associations were estimated using multinomial logistic regression models. To account for sample selection, we applied inverse probability weighting.

Results: Duration of screen time was stepwise associated with the degree of spinal pain. Compared with those spending $<2 \mathrm{~h} /$ day in front of a screen, screen time of $\geq 6 \mathrm{~h} /$ day was associated with a substantially increased relative risk ratio (RRR) of severe pain for both girls (RRR: 2.49 , 95\% Cl: $2.13-2.92$ ) and boys (RRR: 1.95, 95\% Cl: 1.652.32). Being physical inactive was likewise associated with higher likelihood of severe spinal pain (RRR: 1.22, 95\% Cl: 1.10-1.34) relative to those being moderately active. We observed that being physically active was seemingly associated with lower risk of spinal pain among boys with high frequency of screen time.

Conclusion: Findings indicate that both duration of screen time and physical inactivity are correlated with spinal pain in pre-adolescents with the strongest associations for screen time. Reducing screen time or increasing physical activity might help preventing spinal pain in pre-adolescents, particularly among high frequent screen users. Future prospective studies investigating the causal relationship are necessary.
\end{abstract}

Keywords: Adolescence health, Back pain, Epidemiology, Lifestyle behavior, Musculoskeletal disorder, Prevention, Public health, Screen time, Physical activity

\footnotetext{
* Correspondence: acjo@sund.ku.dk

'Section of Epidemiology, Department of Public Health, Faculty of Health and Medical Science, University of Copenhagen, Oster Farimagsgade 5, Box 2099, DK-1014 Copenhagen K, Denmark

Full list of author information is available at the end of the article
}

(C) The Author(s). 2021 Open Access This article is licensed under a Creative Commons Attribution 4.0 International License, which permits use, sharing, adaptation, distribution and reproduction in any medium or format, as long as you give appropriate credit to the original author(s) and the source, provide a link to the Creative Commons licence, and indicate if changes were made. The images or other third party material in this article are included in the article's Creative Commons licence, unless indicated otherwise in a credit line to the material. If material is not included in the article's Creative Commons licence and your intended use is not permitted by statutory regulation or exceeds the permitted use, you will need to obtain permission directly from the copyright holder. To view a copy of this licence, visit http://creativecommons.org/licenses/by/4.0/ The Creative Commons Public Domain Dedication waiver (http://creativecommons.org/publicdomain/zero/1.0/) applies to the data made available in this article, unless otherwise stated in a credit line to the data. 


\section{Introduction}

Spinal pain (i.e., neck, mid back and/or low back pain) constitutes a health burden already from the age of 10 [1]. Epidemiological studies aiming to clarify and understand the etiology of spinal pain in children are scarce, but factors such as symptoms of depression [2, 3], stress and poor general well-being [4], as well as living in socioeconomically disadvantaged families [1] and being exposed to pain in early postnatal life [5] have been suggested as potential risk factors.

Screen-based activities have become ubiquitous components in most families and in educational settings. This fuels young people with an extensive amount of daily screen time, displacing time from a more active lifestyle. Screen-based activities poses different postural demands on the spine; however, common for the activities is nevertheless the static and rigid bodily postures relative to the screen, resembling ergonomic stressors [6-8]. Accordingly, recent and smaller studies have linked different types of sedentary activities such as computers, digital games, TV's, tablet and smartphones with musculoskeletal outcomes, including spinal pain, in adolescents [9-13].

The World Health Organization (WHO) recommends children to engage in at least $60 \mathrm{~min}$ of moderate-tovigorous activity daily to improve health, including musculoskeletal health, and to prevent non-communicable diseases [14]. Evidence regarding the impact of physical activity behaviors on the development of spinal pain is contradicting [15-19]. Some studies suggest no association $[16,17]$. Two prospective studies pointed toward a $\mathrm{u}$-shaped distribution as moderate intensity of physical activity had a potential protective effect, whereas inactivity and vigorous activity (i.e., highly intensive sports activities) increased the risk of back pain $[15,20]$. On the contrary, high level of physical activity was also suggested to protect against low and mid back pain in early adolescence [18].

It is plausible that the emergence of screen-based activities has introduced a new risk factor for preadolescence spinal pain. Naturally it follows that time spent on screen-based activities displaces time from being physically active since there is limited hours of daily leisure time, and thereby eliminating the potential protective effect of a physically active lifestyle in regard to spinal pain [21]. Increased understanding of the interplay between screen-based activities and physical activity behavior is crucial for policy makers in their design of polices and interventions to approach poor lifestyle behaviors; thus, preventing negative health outcomes. Therefore, we aimed to investigate how time spent on screen-based activities and physical activity behavior were associated with spinal pain in pre-adolescents and further to evaluate the potential heterogenous effect of screen time on spinal pain across levels of physical activity using data collected in the large-scale Danish $\mathrm{Na}$ tional Birth Cohort (DNBC).

\section{Methods \\ Study participants}

This study was conducted as a cross-sectional study using data from children participating in the 11-year follow-up (DNBC-11) of DNBC. DNBC is a populationbased cohort of children born in Denmark from 1996 through 2003. Children and their mothers were followed with several follow-ups from pregnancy and through childhood to young adulthood [22]. DNBC-11 were carried out in the period from July 2010 to September 2014, where children received a web-based selfadministered questionnaire to respond from home around their 11th birthday. The questionnaire was pilot tested in focus-group interviews for content validity of each question and functionality. Further details of DNBC and DNBC-11 are described elsewhere (www.dnbc.com) [22]. The study population in the present study consisted of 45,555 11-12-year-olds that participated in DNBC-11 and provided full information on explanatory and outcomes measures (Fig. 1).

All registries applied were available and processed in Statistics Denmark and were linked to DNBC-data through the unique personal identification number assigned to all persons with a permanent residence in Denmark (CPR-number) [23]. However, no personal identifiable data were accessible.

\section{Screen time}

In DNBC-11 the children were asked to report how much of their leisure time they were spending 1) in front of the computer, 2) on computer gaming (i.e., on computer, PlayStation, XBox, PSP, Nintendo and Wii), and 3) watching TV/films. All questions were reported separately for weekdays and weekend days. For weekdays the response categories were given on a seven-point scale ranging from less than $1 / 2$ hour to more than $5 \mathrm{~h}$, and for weekend days on a 10-point scale ranging from less than $1 / 2$ hour to more than $8 \mathrm{~h}$ (Exact phrasing can be found on www.dnbc.dk). Since item 1 and 2 were not mutually exclusive, we created two different exposure variables. For the main analyses, we defined daily screen time by summing hours spent in front of the computer and reported hours spent on TV watching. We calculated the total daily average by assigning weights to the estimates of weekdays and weekend days (weekdays $5 / 7$, weekend days 2/7). Based on this continuous variable, we constructed the following categorical variable consisting of four consecutive groups: $<2 \mathrm{~h} /$ day, 2 to $<4 \mathrm{~h} /$ day, from 4 to $<6 \mathrm{~h} /$ day, $\geq 6 \mathrm{~h} /$ day. In addition to this variable, we constructed a secondary definition of screen time based 


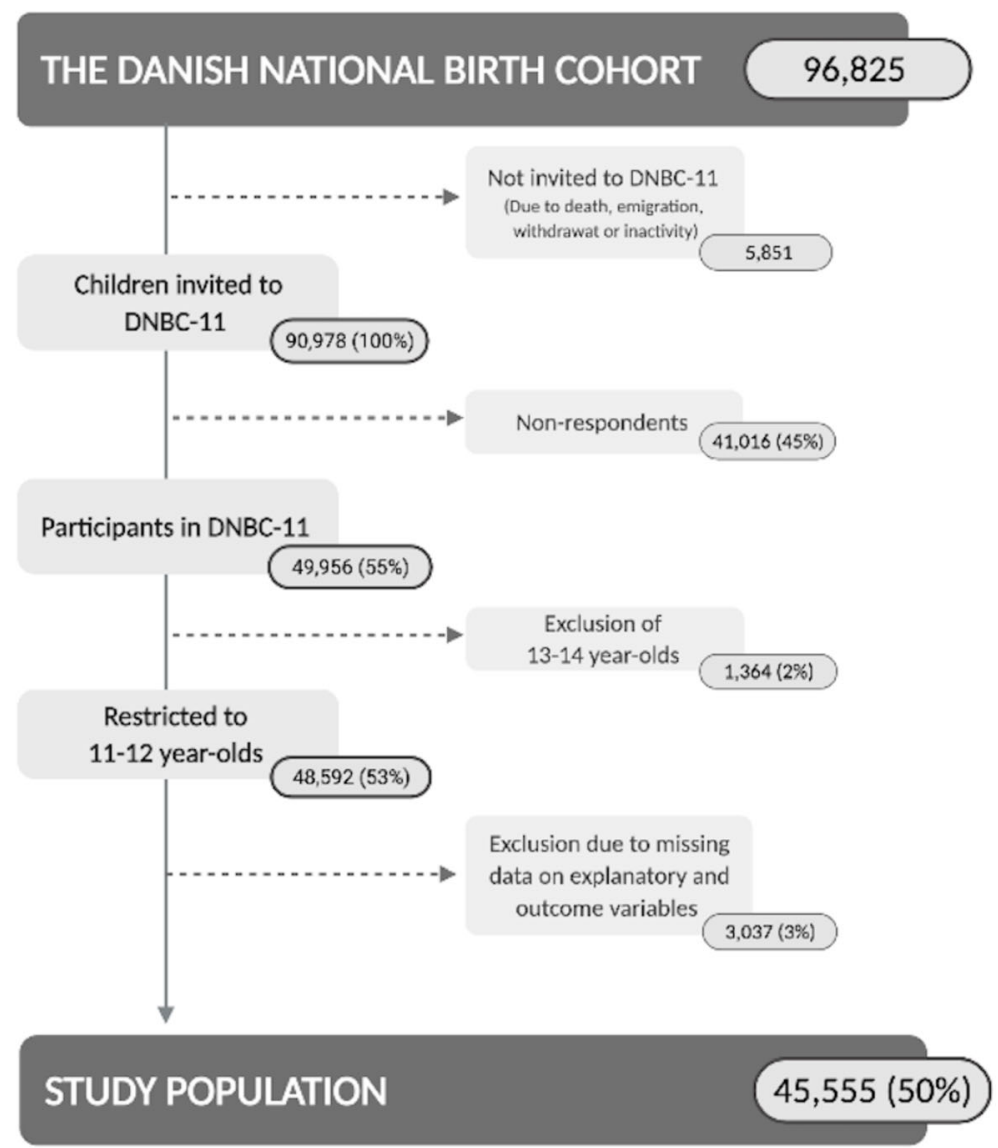

Fig. 1 Flow chart of the eligible study population from all liveborn children in The Danish National Birth Cohort

on time spent with computer gaming etc. and TV watching. This variable was generated similar to the main variable.

\section{Physical activity behavior}

We created two variables for physical activity behavior based on self-reported information regarding general activity level in school breaks and in leisure time, engagement in organized sport activities in leisure time and biking to and from school. Our definition of physical activity behavior was based on WHO's definition of physical activity among children and young people. WHO's definition includes activities such as games, playing, sports, transportation, recreation, physical education and planned exercise in the context of family, school and community activities, and also recommends that physical activities should accumulate minimum 60 min daily [14].

Our main variable was categorized into four consecutive groups: Inactive; lightly active; moderately active; vigorously active. Due to power limitations in interaction analyses, we simplified the physical activity variable into a binary index categorized as physically active vs. physically inactive. The inactive group in the binary variable remained identical to the inactive group in the categorical variable and represented children that in general were defining themselves as being inactive during the day. Exhaustive explanation of the variables and the definition of the different categories can be found in Additional file 1.

\section{Self-reported spinal pain}

DNBC-11 included a sub-division of The Young Spine Questionnaire (YSQ) [24]. The YSQ is designed to measure neck, mid and low back pain in 9-11 year-olds with questions on pain frequency (often/once in a while/once or twice/never) and intensity (from 1:"No pain" to 6:" Very much pain" based on the Faces Pain Scale-Revised (FPS-r)) [24, 25]. For each spinal region we combined pain frequency and intensity and trichotomized into no pain, moderate pain or severe pain. For all spinal regions, severe pain was defined as pain of 4 or more on FPS-r and occurring at least 'once in a while', and no pain was defined as pain of 0,1 or 2 on FPS-r occurring 'once in a while' or 'once or twice'. Moderate pain covered the remaining combinations. Subsequently, spinal pain was constructed as a composite measure including 
all spinal regions categorized according to severity. The applied definition is directly adopted from our previous work on spinal pain and exhaustively explained and illustrated in the study by Joergensen et al. 2019 [1] in which prevalence of spinal pain for the same population can be explored.

\section{Covariates}

A priori, we selected potential confounders, identified using the methods of causal diagrams [26] and supported by experience from our previous work [1].

Information on child's sex, age and family type was derived from DNBC-11. Parity was obtained from The Danish Medical Birth Registry [27]. Information on parental education was obtained from The Danish Population's Education Register [23]. Educational level was operationalized as the highest completed education of the parents attained the year of the child's 11th birthday and was categorized into three groups according to the International Standard Classification of Education (ISCE D) 2011: low (ISCED 0-2), medium (ISCED 3-4) and high (ISCED 5-8) [28]. Equivalized household income the year of the child's 11th birthday was based on disposable household income extracted from The Income Statistics Register [29]. We divided disposable household income by an equivalence factor corresponding to the modified OECD scale [30]. This enabled comparison of family income across family size and composition. We further categorized equivalized household income into quartiles by year relative to all mothers giving birth in the given year.

\section{Statistics}

We applied multinomial logistic regression models to calculate crude and adjusted relative risk ratios (RRR) and corresponding 95\% confidence intervals (CI) for the association between screen time and physical activity behavior, respectively, and spinal pain. In all analyses, children with no spinal pain were considered the reference outcome. The dependency between siblings in the sample $(n=6076)$ was taken into account by applying a robust standard error estimator [31]. All statistical analyses were performed in STATA V. 16.1.

Due to the assumption that screen and physical activity behavior may differ between boys and girls and since girls report more spinal pain, we a priori decided to explore sex-differences evaluating first-order interactions between child's sex and screen time, and between child's sex and physical activity using Wald-tests. Since the tests indicated interaction for screen time $(P=0.059)$, but not for physical activity $(P=0.877)$, we included the interaction between child's sex and screen time together with the main effects of physical activity in model 2 , and in model 3 we further adjusted for the covariates listed above.

We evaluated the possible heterogenous effect of screen time on spinal pain across levels of physical activity by Wald-testing the three-way interaction between sex, screen time and physical activity behavior. Further, we made a 'loss to follow-up analysis' to evaluate whether selection forces in regard to participation in DNBC-11 may have biased our results [32]. Additionally, we used inverse probability weighting (IPW) to account for the study population being a selected sample of the source population [33]. For the latter, we used a reference population consisting of all children born in Denmark between 1996 and 2003 and alive at their 11th birthday $(n=526,194)$. The probability of participation in the study was estimated for each individual using a given set of variables predicting selection into the cohort and loss to follow-up. These factors included parental education at birth, equivalised household income the year before birth, parity, urbanization, maternal smoking during pregnancy and maternal age at birth. All these variables were obtained from Statistic Denmark and therefore available for all participants as well as nonparticipants. We hereto estimated a weight for each child (i.e., the inverse of the probability of selection) such that each participant was representing not only him/herself but also children with similar characteristics that did not participate in the study. Further, instead of excluding all the individuals for which some of the prediction variables were missing, we estimated the weights based on the best possible set of existing prediction variables.

Lastly, we examined the robustness of the results by conducting a number of sensitivity analyses. Firstly, we performed analyses using neck, mid and low back pain as separate outcomes. Secondly, we used our secondary definition of screen time, and thirdly, we restricted the study population to only include 11 -year-olds to accommodate potential age trends. Lastly, since concerns have been raised regarding the importance of mental health $[4,34]$, we decided to do a sub-analysis in which we adjusted for general wellbeing and stress in children.

\section{Results}

Almost half of the study participants spent 2 to $<4 \mathrm{~h} /$ day on screen time, whereas $22 \%$ spent $<2 \mathrm{~h}$ /day, and almost $9 \%$ spent $\geq 6 \mathrm{~h} /$ day (Table 1 ). This distribution varied slightly between boys and girls i.e., boys spent more time than girls. Study participants spending gradually more time on screens daily differed from their peers spending $<2 \mathrm{~h} /$ day with characteristics pointing toward lower socio-economic status, as well as they had siblings and did not live with both of their parents (Table 1). Similar patterns were seen for decreasing level of 
Table 1 Characteristics of the 45,555 pre-adolescents included in the study population according to the main exposure status (screen-based activity) (11-year follow-up, The Danish National Birth Cohort, 1996-2003)

\begin{tabular}{|c|c|c|c|c|c|}
\hline \multirow[b]{2}{*}{ Characteristics } & \multirow[b]{2}{*}{$\mathbf{N}$} & \multicolumn{4}{|c|}{ Average time spent on screen-based activity (h/day) ${ }^{a}$} \\
\hline & & $<2$ & 2 to $<4$ & 4 to $<6$ & $\geq 6$ \\
\hline Total $^{b}$ & $45,555(100)$ & $10,104(22.2)$ & $22,057(48.4)$ & $9452(20.8)$ & $3942(8.7)$ \\
\hline \multicolumn{6}{|l|}{ Physical activity behavior } \\
\hline Inactive & $5201(11.4)$ & $753(7.5)$ & $2251(10.2)$ & $1366(14.5)$ & $831(21.6)$ \\
\hline Lightly active & $20,436(44.9)$ & $4186(41.5)$ & $9730(44.1)$ & $4544(48.1)$ & $1973(49.3)$ \\
\hline Moderately active & $17,853(39.2)$ & $4519(44.7)$ & $9065(41.1)$ & $3218(34.1)$ & $1051(26.7)$ \\
\hline Vigorously active & $2065(4.5)$ & $643(6.4)$ & $1011(4.6)$ & $324(3.4)$ & $87(2.2)$ \\
\hline \multicolumn{6}{|l|}{ Sex } \\
\hline Boys & $21,711(47.7)$ & $3686(36.5)$ & $10,177(46.1)$ & $5355(56.7)$ & $2493(63.2)$ \\
\hline Girls & $23,844(52.3)$ & $6418(63.5)$ & $11,880(53.9)$ & $4097(43.4)$ & $1449(36.8)$ \\
\hline \multicolumn{6}{|l|}{ Age } \\
\hline 11 years & $38,326(84.1)$ & $8943(88.5)$ & $18,784(85.2)$ & 7599 (80.4) & $3000(76.1)$ \\
\hline 12 years & 7229 (15.9) & $1161(11.5)$ & $3273(14.8)$ & $1853(19.6)$ & $942(23.9)$ \\
\hline \multicolumn{6}{|l|}{ Parental educational level ${ }^{\mathrm{c}}$} \\
\hline High & $30,629(67.2)$ & $7389(73.1)$ & $14,994(68.10)$ & $5987(63.3)$ & $2259(57.3)$ \\
\hline Medium & $14,100(31.0)$ & $2579(25.5)$ & $6699(30.4)$ & $3276(34.7)$ & $1546(39.2)$ \\
\hline Low & $826(1.8)$ & $136(1.4)$ & $364(1.7)$ & $189(2.0)$ & $137(3.5)$ \\
\hline \multicolumn{6}{|l|}{ Equivalised household income ${ }^{c}$} \\
\hline 4th quartile (highest) & $16,333(35.9)$ & $4082(40.4)$ & 8095 (36.7) & $3055(32.3)$ & $1101(27.9)$ \\
\hline 3rd quartile & $14,011(30.8)$ & $2996(29.7)$ & $6848(31.1)$ & $3010(31.9)$ & $1157(29.4)$ \\
\hline 2nd quartile & $10,225(22.4)$ & 2006 (19.9) & $4836(22.0)$ & 2259 (23.9) & $1124(28.5)$ \\
\hline 1st quartile (lowest) & $4986(11.0)$ & $1020(10.1)$ & $2278(10.3)$ & $1128(12.0)$ & $560(14.2)$ \\
\hline \multicolumn{6}{|l|}{ Family type } \\
\hline Living with both parents & $35,638(78.2)$ & $8110(80.3)$ & $17,449(79.1)$ & $7193(76.1)$ & $2886(73.2)$ \\
\hline Not living with (both) parents ${ }^{\mathrm{d}}$ & 9917 (21.8) & $1994(19.7)$ & $4608(20.9)$ & $2259(23.9)$ & $1056(26.8)$ \\
\hline \multicolumn{6}{|l|}{ Parity $^{\mathrm{e}}$} \\
\hline Nulliparous & $21,976(48.2)$ & $5498(54.4)$ & $10,755(48.6)$ & $4152(43.9)$ & $1571(39.9)$ \\
\hline Parous & $23,579(51.8)$ & $4606(45.6)$ & $11,302(51.4)$ & $5300(56.1)$ & $2371(60.2)$ \\
\hline
\end{tabular}

a Variables were analyzed with the chi-squared test of heterogeneity. Chi-squared tests were statistically significant for all variables

${ }^{\mathrm{b}}$ For total distribution of screen-based activity row percentage is shown; for all the covariates column percentages are shown

' Measured the year of the child's 11 th birthday

$\mathrm{d}$ Parents not living together due to divorce, separation, they never lived together or only one parent alive

e Maternal parity status in index pregnancy

physical activity (Additional file 1). Comparing the two screen time definitions showed that girls spent more time in front of the computer (i.e., homework etc.) than with computer gaming (Additional file 2).

\section{Association between screen time, physical activity behavior and spinal pain}

The risk ratio of having moderate or severe spinal pain at age 11-12 relative to no pain increased stepwise with increasing screen time (Table 2). The associations were only slightly attenuated subsequent to adjustment for potential confounding (Table 2, model 3). Compared with those spending $<2 \mathrm{~h} /$ day on screen time, screen time of $\geq 6 \mathrm{~h} /$ day was associated with a substantial increased risk ratio of reporting severe pain for both girls (RRR: $2.49,95 \%$ CI: $2.13-2.92$ ) and boys (RRR: 1.95 , 95\% CI: $1.65-2.32$ ). The associations appeared stronger for severe than for moderate pain among those spending $\geq 6$ $\mathrm{h} /$ day on screen time. Analysis of physical activity indicated a u-shape for severe spinal pain. Comparing with the moderately active pre-adolescents (RRR: 1.00), lightly (RRR: 1.09 , 95\% CI: 1.02-1.16) and vigorously active (RRR: 1.09 , 95\% CI: 1.02-1.16) had similar increased risk ratio, while inactive pre-adolescents had the highest likelihood of spinal pain (RRR: 1.22, 95\% CI: 1.10-1.34) (Table 2). 
Table 2 Relative risk ratio (RRR) of spinal pain according to screen time and physical activity among the 45,555 pre-adolescents included in the study population (The Danish National Birth Cohort, born 1996-2003)

\begin{tabular}{|c|c|c|c|c|c|c|c|}
\hline & \multirow[b]{2}{*}{$\begin{array}{l}\text { No. of cases } \\
\text { Moderate/Severe }\end{array}$} & \multicolumn{2}{|l|}{ Model $1^{\text {ab }}$} & \multicolumn{2}{|l|}{ Model $2^{\text {bc }}$} & \multicolumn{2}{|l|}{ Model $3^{\text {bd }}$} \\
\hline & & $\begin{array}{l}\text { Moderate pain } \\
\text { RRR }(95 \% \mathrm{Cl})\end{array}$ & $\begin{array}{l}\text { Severe pain } \\
\text { RRR }(95 \% \mathrm{Cl})\end{array}$ & $\begin{array}{l}\text { Moderate pain } \\
\text { RRR }(95 \% \mathrm{Cl})\end{array}$ & $\begin{array}{l}\text { Severe pain } \\
\text { RRR }(95 \% \mathrm{CI})\end{array}$ & $\begin{array}{l}\text { Moderate pain } \\
\text { RRR }(95 \% \mathrm{Cl})\end{array}$ & $\begin{array}{l}\text { Severe pain } \\
\text { RRR }(95 \% \mathrm{CI})\end{array}$ \\
\hline \multicolumn{8}{|l|}{ Screen time, girls } \\
\hline$<2$ h/day & $1734 / 728$ & Ref. & Ref. & Ref. & Ref. & Ref. & Ref. \\
\hline 2 to $<4$ h/day & $3651 / 1584$ & $1.25(1.17-1.34)$ & $1.30(1.18-1.43)$ & $1.24(1.16-1.33)$ & $1.28(1.16-1.41)$ & $1.23(1.15-1.32)$ & $1.24(1.13-1.37)$ \\
\hline 4 to $<6$ h/day & $1372 / 631$ & $1.49(1.37-1.63)$ & $1.64(1.45-1.84)$ & $1.47(1.34-1.61)$ & $1.59(1.41-1.80)$ & $1.43(1.31-1.57)$ & $1.49(1.32-1.68)$ \\
\hline$\geq 6$ h/day & $493 / 332$ & $1.80(1.58-2.05)$ & $2.89(2.48-3.38)$ & $1.76(1.54-2.01)$ & $2.77(2.37-3.24)$ & $1.69(1.48-1.93)$ & $2.49(2.13-2.92)$ \\
\hline \multicolumn{8}{|l|}{ Screen time, boys } \\
\hline$<2$ h/day & $973 / 283$ & Ref. & Ref. & Ref. & Ref. & Ref. & Ref. \\
\hline 2 to $<4$ h/day & 2856/922 & $1.11(1.02-1.22)$ & $1.24(1.07-1.43)$ & $1.11(1.01-1.21)$ & $1.23(1.06-1.41)$ & $1.10(1.01-1.20)$ & $1.21(1.05-1.39)$ \\
\hline 4 to $<6$ h/day & $1652 / 553$ & $1.31(1.19-1.44)$ & $1.51(1.29-1.76)$ & $1.29(1.17-1.41)$ & $1.47(1.26-1.71)$ & $1.26(1.15-1.39)$ & $1.41(1.20-1.64)$ \\
\hline$\geq 6$ h/day & $761 / 355$ & $1.38(1.23-1.55)$ & $2.21(1.87-2.62)$ & $1.34(1.19-1.50)$ & $2.11(1.78-2.51)$ & $1.30(1.16-1.46)$ & $1.95(1.65-2.32)$ \\
\hline \multicolumn{8}{|c|}{ Physical activity behavior } \\
\hline Inactive & $1627 / 769$ & $1.25(1.16-1.33)$ & $1.56(1.42-1.71)$ & $1.14(1.06-1.22)$ & $1.28(1.16-1.41)$ & $1.12(1.04-1.20)$ & $1.22(1.10-1.34)$ \\
\hline Lightly active & $6225 / 2474$ & $1.14(1.09-1.19)$ & $1.20(1.12-1.28)$ & $1.11(1.06-1.16)$ & $1.12(1.05-1.20)$ & 1.09 (1.04-1.14) & $1.09(1.02-1.16)$ \\
\hline Moderately active & $5066 / 1914$ & Ref. & Ref. & Ref. & Ref. & Ref. & Ref. \\
\hline Vigorously active & $574 / 231$ & $0.98(0.88-1.09)$ & $1.04(0.90-1.21)$ & $1.00(0.90-1.11)$ & $1.09(0.94-1.26)$ & $1.00(0.90-1.11)$ & $1.08(0.93-1.26)$ \\
\hline
\end{tabular}

${ }^{a}$ Crude model (Screen time was analyzed as the interaction between screen time and child's sex)

${ }^{\mathrm{b}}$ Reference categories: For explanatory variables; less than $2 \mathrm{~h}$ of daily screen time and being physically active, and for outcome variables; not having reported moderate or severe spinal pain in DNBC-11 (No pain)

' Simultaneously modelled for the interaction between screen time and child's sex, and physical activity behavior, but without further adjustments

d Adjusted for child's age, parity, family type, parental education, household income and simultaneously modelled for the interaction between screen time and child's sex, and physical activity behavior

Modeling screen time and physical activity behavior simultaneously (Table 2, model 2), the relative changes in estimates compared with those from the crude analyses were negligible for screen time, but more pronounced for physical inactivity, suggesting that the effect of physical activity on spinal pain may be partially explained by screen time.

Indication of interaction between child's sex, screen time and physical activity was observed $(P=0.08)$, showing that being physically active was seemingly associated with lower risk of severe spinal pain among boys with high frequency of screen time (Fig. 2).

No remarkable differences were revealed when investigating the spinal regions separately (Additional file 4, 5 and 6), nor when applying the secondary screen time definition (Additional file 7), or when restricting the analytical sample to include 11-year-olds only (Additional file 8). However, when adjusting for general wellbeing and stress in children, the associations were diminished for screen time and almost removed for physical activity (Additional file 9).

\section{Selection of study participants}

Pre-adolescents lost to follow-up constituted 50\% and their characteristics pointed toward lower socioeconomic status, not being first-born and living outside urban areas (Additional file 10). However, the weighted analyses in which we applied IPW to account for selection both into to the cohort and from attrition showed no essential changes to the estimates (Additional file 11).

\section{Discussion}

In this study of more than 45,000 pre-adolescents from DNBC, we demonstrated that increasing screen time were stepwise associated with increased likelihood of both moderate and severe spinal pain in pre-adolescents. Further, physically inactive pre-adolescents were more likely to report severe spinal pain than the more active pre-adolescents, and the associations were indicative for a u-shape. Lastly, we demonstrated that being physically active was seemingly associated with lower risk of spinal pain among boys with high frequency of screen time.

Our results complement the previous literature showing that the risk of spinal pain in children and adolescents increases monotonously with increasing hours spent in front of a screen [9-11]. We further showed that the association with screen time was independent of physical activity. This is in line with two studies indicating that the association between sedentary activities and physical complaints in young people is not attributable to physical activity behavior [11, 12], and a meta-analysis suggesting sedentary and physical activity to be separate 

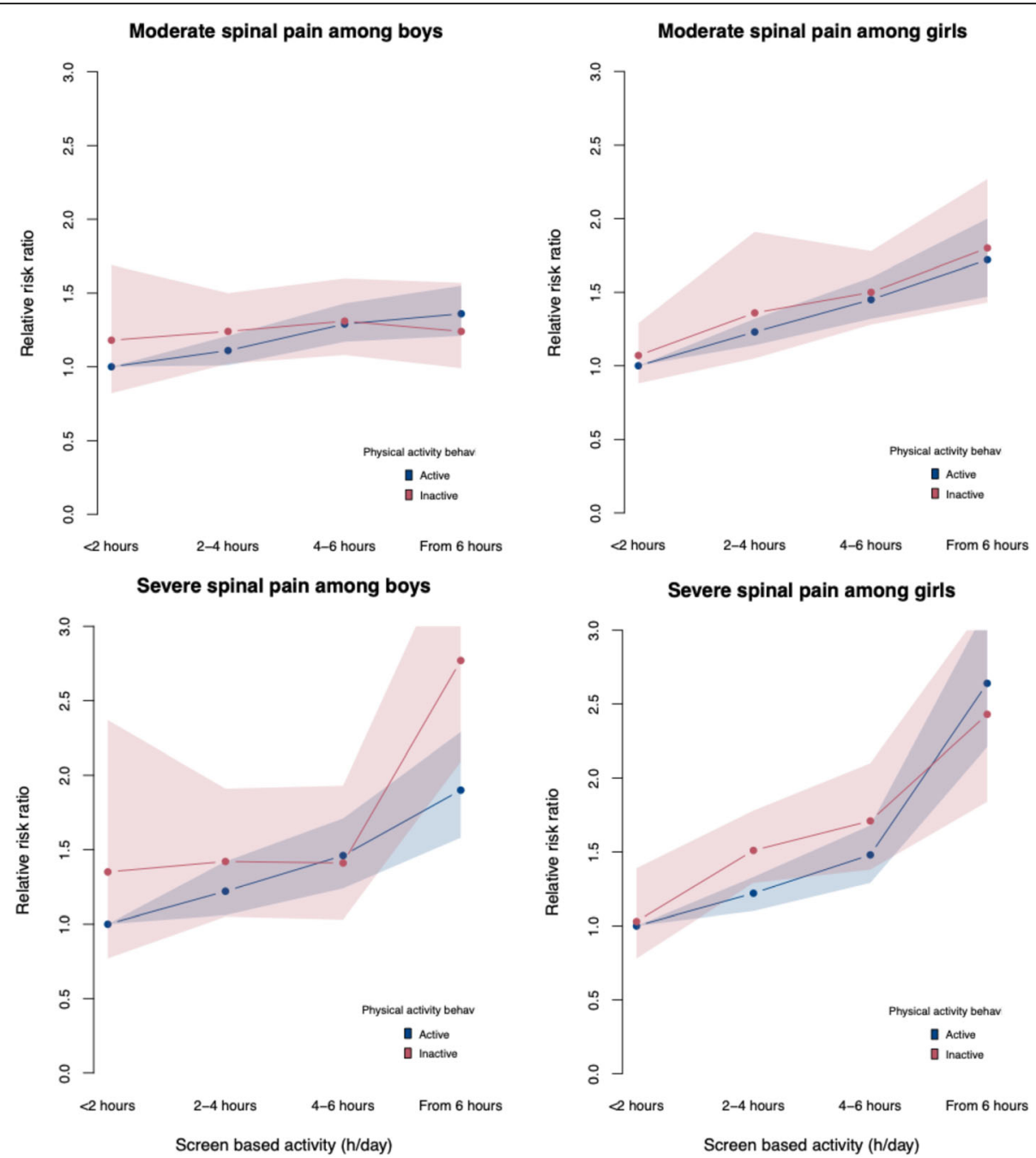

Fig. 2 Plots of interaction between child's sex, screen time and physical activity behavior on spinal pain in pre-adolescents $(N=45,555)$. Test of interaction: $P=0.08$. Adjusted for child's age, parity, family type, parental education and household income

constructs that independently of each other impact on health outcomes [35]. We did, however, observe that some of the crude effect of physical inactivity was attributable to screen time, but not vice versa.

For severe spinal pain, we observed tendencies of a $\mathrm{u}$-shaped association with physical activity. A smallerscale Danish prospective study, with accelerometer measurements of physical activity, showed that shifting from inactive to moderate intensity of activities tended to protect against spinal pain while vigorous physical activity increased the risk of developing spinal pain [19]. Increased risk of developing spinal pain was likewise observed in the $10 \%$ most active adolescents in a school-based prospective study [36]. In other studies, the u-shape has not been replicated $[16,17]$. Besides differences in methods of measurement which may challenge direct comparisons of study results, the lack of a clear negative impact of vigorously activity on spinal pain may be explained by limitations in our data that obstructing us from distinguishing pre-adolescents performing highly intensive sport disciplines, presumably being those at highest risk $[15,19,36]$. However, from a public health perspective, these results suggest that the intensity of physical activity is important for the relationship between physical activity behavior and spinal pain in pre-adolescence.

As screen-based activities and physical activity behavior both may cause or take part in the development of spinal pain $[6,12,18]$, we expected to find a heterogenous effect of screen time on spinal pain across the levels of physical activity; however, this was only the case for severe spinal pain among boys. The lack of a clear interaction between the two lifestyle behaviors is likely due to differential impact of sedentary and physical behavior on musculoskeletal health i.e., different impact on different spinal regions. 
We have previously with DNBC-11 showed that preadolescents with low general wellbeing or high stress levels had higher odds of spinal pain in a cross-sectional design [4]. Therefore, we included the two measures as additional confounders in a sensitivity analysis, which diminished the association with screen time and almost removed the association for physical activity. However, since the temporality is highly uncertain, and wellbeing, stress and spinal pain in principle can be expressions of the same thing i.e., feeling bad, we believe that such adjustment would implicate overadjustment.

The mechanisms whereby sedentary and physical activity contribute to the development of spinal pain remains somewhat unknown. For example, spending a high amount of time sedentary displaces time from a more active lifestyle which may result in overweight as well as affecting sleep quality [37-39]. Both problematic sleep and $\mathrm{BMI}>25 \mathrm{Kg} / \mathrm{m}^{2}$ have previously been suggested to be associated with the development of musculoskeletal pain [40-44]. However, since physical inactivity and screen time are modifiable behaviors, there seems to be an urgent need for effective populationbased strategies.

\section{Strengths and limitations}

The large sample size resulted in stable estimates and sufficient numbers in each of the exposure categories. A further strength is the application of YSQ to measure spinal pain. This instrument has previously been validated among Danish children of 9-11 years of age, and proven to have applicability in cross-sectional studies [24]. Lastly, DNBC is nested within the Danish population; thus, we were able to make individual linkage to health and social data on pre-adolescents and their parents from Danish nationwide registries enabling adjustment for important potential confounders and further to analyze non-participation according to the source population and to attrition.

Limitations include the cross-sectional design and selfreported screen time and physical activity behavior. The cross-sectional design obstructs examination of temporality. One could argue that pre-adolescents with spinal pain refrain from being physically active and thus, spending more time in front of a screen and vice versa. Hence, the study was restricted to investigate the contemporary correlations in the data, exclusively, and no conclusive statements concerning causal directions of the associations have been made.

Misclassification of self-reported sedentary and physical behavior is a general problem in studies on this issue $[11,45,46]$. In this study, the items were only pilot tested for content validity and functionality, but not further tested for reliability and concurrent validity. Moreover, mutually exclusiveness was not given, as the activity across media types might overlap in time which we were not able to completely account for with the collected data [11]. Further, parallel to the DNBC-11 data collection, the iPad was launched. Additionally, in 2011 $50 \%$ of all Danish 10-12 year-olds had a smartphone, and this percentage has increased rapidly since 2011 [47]. Due to tablets being strong, integrated components in families and educational settings today, the emergence of tablets during and subsequent to the period of the data collection (2010-2014) might have resulted in a shift in screen-environment among children. In addition, the general use of electronic devices has likewise increased rapidly over the last decade. Therefore, the prevalence estimates of screen time might be higher today than by the time DNBC-11 was carried out. Additionally, the applied variable of physical activity behavior was based on a combination of volume, intensity, context and children's perception of being active defined in line with WHO's recommendations for physical activity among children and young people [14]. However, the current WHO recommendation of a minimum of 60 daily minutes of moderate to vigorous activities could only be approximated. Despite this, we believe that the applied definition in this work constituted a more compliant measure for this age group than would a proxy based exclusively on attendance in sport activities.

Finally, selection bias cannot be neglected as DNBCparticipants are a selected sample of the source population [32]. However, we accounted for sample selection by applying IPW $[33,48]$, and the weighted results did not reveal any essential changes to the estimates; therefore, we do not consider selection bias as a major problem for the study findings [32, 49].

\section{Conclusion}

Findings indicate that duration of screen time and physical inactivity are correlated with spinal pain in preadolescents with the strongest associations for screen time. Reducing screen time or increasing physical activity might help preventing spinal pain in pre-adolescents, particularly among high frequent screen users. Future prospective studies investigating the causal relationship between screen time, physical activity and development of spinal pain in children and adolescents are necessary as further understanding of the interplay is of great public health relevance.

\section{Abbreviations}

DNBC: The Danish National Birth Cohort; DNBC-11: The 11-year follow-up of The Danish National Birth Cohort; FPS-r: Faces Pain Scale-Revised; IPW: Inverse probability weighting; ISCED: International Standard Classification of Education; RRR: Relative risk ratio; Spinal pain: Neck pain, mid back pain and/or low back pain; YSQ: The Young Spine Questionnaire; 95\% Cl: $95 \%$ confidence intervals 


\section{Supplementary Information}

The online version contains supplementary material available at https://doi. org/10.1186/s12891-021-04263-z.

\section{Additional file 1. \\ Additional file 2. \\ Additional file 3. \\ Additional file 4. \\ Additional file 5 . \\ Additional file 6 . \\ Additional file 7. \\ Additional file 8. \\ Additional file 9. \\ Additional file 10. \\ Additional file 11.}

\section{Acknowledgements}

The Danish National Birth Cohort was established with a significant grant from the Danish National Research Foundation. Additional support was obtained from the Danish Regional Committees, the Pharmacy Foundation, the Egmont Foundation, the March of Dimes Birth Defects Foundation, the Health Foundation and other minor grants. The DNBC Biobank has been supported by the Novo Nordisk Foundation and the Lundbeck Foundation. Follow-up of mothers and children have been supported by the Danish Medical Research Council (SSVF 0646, 271-08-0839/06-066023, O602-01042B, 0602-02738B), the Lundbeck Foundation (195/04, R100-A9193), The Innovation Fund Denmark 0603-00294B (09-067124), the Nordea Foundation (02-2013-2014), Aarhus Ideas (AU R9-A959-13-S804), University of Copenhagen Strategic Grant (IFSV 2012), and the Danish Council for Independent Research (DFF - 4183-00594 and DFF - 4183-00152).

\section{Authors' contributions}

ACJ conceptualized and designed the study, contributed to methods development including operationalization of variables, carried out data management, analyses and interpretation of results, and drafted the manuscript. Prof AMNA and Dr. KSL designed the data collection instruments, conceptualized and designed the study, and contributed to methods development including operationalization of variables, interpretation of results and critical revision of the manuscript. Prof PKA supervised the statistical methods and analyses and contributed to method development, interpretation of results and critical revision of the manuscript. Prof LH conceptualized and designed the study, contributed to methods development, interpretation of results and critical revision of the manuscript. All authors approved the final manuscript as submitted and agree to be accountable for all aspects of this article.

\section{Funding}

The study was supported by The Danish Council for Independent Research (DFF-7016-00344). The funder/sponsor did not participate in the work.

\section{Availability of data and materials}

All data were accessed and analyzed via a safe remote access connection to Statistics Denmark. Availability of these data is restricted to research institutions with approved license such as the Danish public universities. The applied data in this study are therefore not publicly available. Access to data can be given upon reasonable request and with permission from Statistics Denmark.

\section{Declarations}

\section{Ethics approval and consent to participate}

Approval of the study was obtained from the Danish Data Protection Agency through the joint notification of The Faculty of Health and Medical Sciences at The University of Copenhagen (SUND-2017-09) and the DNBC Steering Committee (2017-23).

\section{Consent for publication}

Not applicable.

\section{Competing interests}

The authors declare that they have no competing interests.

\section{Author details}

${ }^{1}$ Section of Epidemiology, Department of Public Health, Faculty of Health and Medical Science, University of Copenhagen, Oster Farimagsgade 5, Box 2099, DK-1014 Copenhagen K, Denmark. ${ }^{2}$ Section of Biostatistics, Department of Public Health, Faculty of Health and Medical Science, University of Copenhagen, Copenhagen, Denmark. ${ }^{3}$ Department of Sport Science and Clinical Biomechanics, University of Southern Denmark, Odense, Denmark. ${ }^{4}$ Nordic Institute of Chiropractic and Clinical Biomechanics, Odense, Denmark.

Received: 25 January 2021 Accepted: 9 April 2021 Published online: 26 April 2021

\section{References}

1. Joergensen AC, Hestbaek L, Andersen PK, Nybo Andersen AM. Epidemiology of spinal pain in children: a study within the Danish National Birth Cohort. Eur J Pediatr. 2019;178(5):695-706. https://doi.org/10.1007/ s00431-019-03326-7.

2. Diepenmaat AC, van der Wal MF, de Vet HC, Hirasing RA. Neck/shoulder, low back, and arm pain in relation to computer use, physical activity, stress, and depression among Dutch adolescents. Pediatrics. 2006;117(2):412-6. https://doi.org/10.1542/peds.2004-2766.

3. Myrtveit SM, Sivertsen B, Skogen JC, Frostholm L, Stormark KM, Hysing M. Adolescent neck and shoulder pain--the association with depression, physical activity, screen-based activities, and use of health care services. J Adolescent Health. 2014;55(3):366-72. https://doi.org/10.1016/j.jadohealth.2 014.02.016.

4. Stallknecht SE, Strandberg-Larsen K, Hestbaek L, Nybo AA. Spinal pain and co-occurrence with stress and general well-being among young adolescents: a study within the Danish National Birth Cohort. Eur J Pediatr. 2017;176(6):807-14. https://doi.org/10.1007/s00431-017-2915-y.

5. Joergensen AC, Lucas R, Hestbaek L, Andersen P, Nybo Andersen AM. Earlylife programming of pain sensation? Spinal pain in pre-adolescents with pain experience in early life. Eur J Pediatr. 2019;178(12):1903-11. https://doi. org/10.1007/s00431-019-03475-9.

6. Straker LM, Coleman J, Skoss R, Maslen BA, Burgess-Limerick R, Pollock CM. A comparison of posture and muscle activity during tablet computer, desktop computer and paper use by young children. Ergonomics. 2008; 51(4):540-55. https://doi.org/10.1080/00140130701711000.

7. Jacobs K, Baker NA. The association between children's computer use and musculoskeletal discomfort. Work (Reading, Mass). 2002;18(3):221-6.

8. Gillespie RM. The physical impact of computers and electronic game use on children and adolescents, a review of current literature. Work (Reading, Mass). 2002;18(3):249-59.

9. Hakala PT, Saarni LA, Punamaki RL, Wallenius MA, Nygard CH, Rimpela AH. Musculoskeletal symptoms and computer use among Finnish adolescents-pain intensity and inconvenience to everyday life: a cross-sectional study. BMC Musculoskelet Disord. 2012;13(1):41. https://doi.org/10.1186/1471-24 74-13-41.

10. Silva GR, Pitangui AC, Xavier MK, Correia-Junior MA, De Araujo RC Prevalence of musculoskeletal pain in adolescents and association with computer and videogame use. J Pediatr. 2016;92(2):188-96. https://doi.org/1 0.1016/j.jped.2015.06.006

11. Torsheim T, Eriksson L, Schnohr CW, Hansen F, Bjarnason T, Valimaa R. Screen-based activities and physical complaints among adolescents from the Nordic countries. BMC Public Health. 2010;10(1):324. https://doi.org/1 0.1186/1471-2458-10-324.

12. Keane E, Kelly C, Molcho M, Nic GS. Physical activity, screen time and the risk of subjective health complaints in school-aged children. Prev Med. 2017;96:21-7. https://doi.org/10.1016/j.ypmed.2016.12.011.

13. Harris C, Straker L, Pollock C, Smith A. Children, computer exposure and musculoskeletal outcomes: the development of pathway models for school and home computer-related musculoskeletal outcomes. Ergonomics. 2015; 58(10):1611-23. https://doi.org/10.1080/00140139.2015.1035762. 
14. World Health Organization. Global recommendations on physical activity for health. Geneva: WHO; 2010. Available at: https://www.who.int/publications/ i/item/9789241599979.

15. Heneweer $H$, Vanhees L, Picavet HSJ. Physical activity and low back pain: a U-shaped relation? Pain. 2009;143(1):21-5. https://doi.org/10.1016/j.pain.2 008.12.033.

16. Aartun E, Hartvigsen J, Boyle E, Hestbaek L. No associations between objectively measured physical activity and spinal pain in 11-15-year-old Danes. Eur J Pain (London, England). 2016;20(3):447-57.

17. Wedderkopp N, Leboeuf-Yde C, Bo Andersen L, Froberg K, Steen HH. Back pain in children: no association with objectively measured level of physical activity. Spine. 2003;28(17):2019-24. https://doi.org/10.1097/01.BRS. 0000083238.78155 .31$.

18. Wedderkopp N, Kjaer P, Hestbaek L, Korsholm L, Leboeuf-Yde C. High-level physical activity in childhood seems to protect against low back pain in early adolescence. Spine J. 2009;9(2):134-41. https://doi.org/10.1016/j. spinee.2008.02.003

19. Franz C, Møller NC, Korsholm L, Jespersen E, Hebert JJ, Wedderkopp N. Physical activity is prospectively associated with spinal pain in children (CHAMPS Study-DK). Sci Rep. 2017;7(1):11598.

20. Franz C, Jespersen $E$, Rexen $C T$, Leboeuf-Yde C, Wedderkopp N. Back injuries in a cohort of schoolchildren aged 6-12: a 2.5-year prospective study. Scand J Med Sci Sports. 2016;26(8):911-8. https://doi.org/10.1111/sms.12519.

21. Pedisic Z, Dumuid D, Olds TS. Intergrating sleep, sedentary beahviour, and physical activity research in the emerging field of time-use epidemiology: Defintions, concepts, statistical methods, theoretical framework, and future directions. Kinesiology (Zagreb, Croatia). 2017;49(2):252.

22. Olsen J, Meder I. Better health for mother and child - the Danish National Birth Cohort (DNBC), its structure, history and aims. Norsk Epidemiologi. 2014:24(1-2):37-8

23. Jensen VM, Rasmussen AW. Danish education registers. Scand J Public Health. 2011:39(7 Suppl):91-4. https://doi.org/10.1177/1403494810394715.

24. Lauridsen $H H$, Hestbaek $L$. Development of the young spine questionnaire. BMC Musculoskelet Disord. 2013;14(1):185. https://doi.org/10.1186/1471-24 74-14-185.

25. Hicks $\mathrm{CL}$, von Baeyer $\mathrm{CL}$, Spafford PA, van Korlaar I, Goodenough B. The faces pain scale-revised: toward a common metric in pediatric pain measurement. Pain. 2001;93(2):173-83. https://doi.org/10.1016/S0304-3 959(01)00314-1.

26. Greenland S, Pearl J, Robins JM. Causal diagrams for epidemiologic research Epidemiology (Cambridge, Mass). 1999;10(1):37-48.

27. Bliddal M, Broe A, Pottegard A, Olsen J, Langhoff-Roos J. The Danish medical birth register. Eur J Epidemiol. 2018;33(1):27-36. https://doi.org/10.1 007/s10654-018-0356-1.

28. ISCED. International standard classification of education ISCED 2011. Montreal: UNESCO Institute for Statistics; 2012.

29. Baadsgaard M, Quitzau J. Danish registers on personal income and transfer payments. Scand J Public Health. 2011;39(7 Suppl):103-5. https://doi.org/1 $0.1177 / 1403494811405098$.

30. OECD. OECD Project on Income Distribution and Poverty. What are the equivalence Scales? : Organization for Economic Cooperation and Development [cited 201819 September ]. Available from: http://www.oecd. org/eco/growth/OECD-Note-EquivalenceScales.pdf.

31. Vach W. Regression models as a tool in medical statistics. Boca Raton: Chapman and Hall/CRC; 2013.

32. Jacobsen T, Nohr E, Frydenberg M. Selection by socioeconomic factors into the Danish National Birth Cohort. Eur J Epidemiol. 2010:25(5):349-55. https://doi.org/10.1007/s10654-010-9448-2.

33. Molenberghs G, Fitzmaurice G, Kenward M, Tsiatis A, Verbeke G. A Review of Handbook of Missing Data Methodology. J Educ Behav Stat. 2015;41(5):5546.

34. Nigg CR, Wunsch K, Nigg C, Niessner C, Jekauc D, Schmidt SCE, et al. Are physical activity, screen time, and mental health related during childhood, preadolescence, and adolescence? 11-year results from the German Motorik-Modul longitudinal study. Am J Epidemiol. 2021;190(2):220-9. https://doi.org/10.1093/aje/kwaa192.

35. Pearson N, Braithwaite RE, Biddle SJH, van Sluijs EMF, Atkin AJ. Associations between sedentary behaviour and physical activity in children and adolescents: a meta-analysis. Obesity Rev. 2014;15(8):666-75. https://doi. org/10.1111/obr.12188
36. Aartun E, Boyle E, Hartvigsen J, Ferreira PH, Maher CG, Ferreira ML, et al. The most physically active Danish adolescents are at increased risk for developing spinal pain: a two-year prospective cohort study. BMJ Open Sport Exerc Med. 2016;2(1):e000097. https://doi.org/10.1136/bmjsem-2015000097.

37. Mitchell JA, Rodriguez D, Schmitz KH, Audrain-Mcgovern J. Greater screen time is associated with adolescent obesity: a longitudinal study of the BMI distribution from Ages 14 to 18. Obesity (Silver Spring, Md). 2013;21(3):572.

38. $\mathrm{Xu} \mathrm{H}$, Wen LM, Hardy LL, Rissel C. Associations of outdoor play and screen time with nocturnal sleep duration and pattern among young children. Acta Paediatr. 2016:105(3):297-303. https://doi.org/10.1111/apa.13285.

39. Ekelund U, Brage S, Froberg K, Harro M, Anderssen SA, Sardinha LB, et al. TV viewing and physical activity are independently associated with metabolic risk in children: the European youth heart study (TV viewing, activity, and metabolic risk). PLoS Med. 2006;3(12):e488. https://doi.org/10.1371/journal. pmed.0030488.

40. Smith MT, Haythornthwaite JA. How do sleep disturbance and chronic pain inter-relate? Insights from the longitudinal and cognitive-behavioral clinical trials literature. Sleep Med Rev. 2004;8(2):119-32. https://doi.org/10.1016/S1 087-0792(03)00044-3.

41. Kundermann B, Krieg J-C, Schreiber W, Lautenbacher S. The effect of sleep deprivation on pain. Pain Res Manag. 2004;9(1):25-32. https://doi.org/10.11 55/2004/949187.

42. Auvinen JP, Tammelin TH, Taimela SP, Zitting PJ, Jarvelin MR, Taanila AM, et al. Is insufficient quantity and quality of sleep a risk factor for neck, shoulder and low back pain? A longitudinal study among adolescents. Eur Spine J. 2010;19(4):641-9. https://doi.org/10.1007/s00586-009-1215-2.

43. Harrison L, Wilson S, Munafò M. Exploring the associations between sleep problems and chronic musculoskeletal pain in adolescents: a prospective cohort study. Pain Res Manage. 2014;19(5):E139-45. https://doi.org/10.11 55/2014/615203

44. Ben Ayed H, Yaich S, Trigui M, Hmida MB, Jemaa MB, Ammar A, et al. Prevalence, Risk Factors and Outcomes of Neck, Shoulders and Low-Back Pain in Secondary-School Children. J Res Health Sci. 2019;19(1):e00440.

45. Bobakova D, Hamrik Z, Badura P, Sigmundova D, Nalecz H, Kalman M. Testretest reliability of selected physical activity and sedentary behaviour HBSC items in the Czech Republic, Slovakia and Poland. Int J Public Health. 2015; 60(1):59-67. https://doi.org/10.1007/s00038-014-0628-9.

46. Liu Y, Wang M, Tynjala J, LV Y, Villberg J, Zhang Z, et al. Test-retest reliability of selected items of health behaviour in school-aged children (HBSC) survey questionnaire in Beijing, China. BMC Med Res Methodol. 2010;10(1):73. https://doi.org/10.1186/1471-2288-10-73.

47. Vilkår B, TDC. Børn har brug for hjælp til gode mobilvaner (Children need help to improve their mobile phone habits): Børns Vilkår; 2014.

48. Seaman SR, White IR. Review of inverse probability weighting for dealing with missing data. Stat Methods Med Res. 2013:22(3):278-95. https://doi. org/10.1177/0962280210395740.

49. Pizzi C, De Stavola B, Merletti F, Bellocco R, dos Santos SI, Pearce N, et al. Sample selection and validity of exposure-disease association estimates in cohort studies. J Epidemiol Community Health. 2011;65(5):407-11. https:// doi.org/10.1136/jech.2009.107185.

\section{Publisher's Note}

Springer Nature remains neutral with regard to jurisdictional claims in published maps and institutional affiliations.

Ready to submit your research? Choose BMC and benefit from:

- fast, convenient online submission

- thorough peer review by experienced researchers in your field

- rapid publication on acceptance

- support for research data, including large and complex data types

- gold Open Access which fosters wider collaboration and increased citations

- maximum visibility for your research: over $100 \mathrm{M}$ website views per year

At $\mathrm{BMC}$, research is always in progress.

Learn more biomedcentral.com/submission 